\title{
Nutritional and metabolic aspects of postprandial lipemia
}

\author{
D Lairon \\ Unité 130-Inserm, \\ 18, avenue Mozart, 13009 Marseille, France
}

(Received 27 November 1995; accepted 3 May 1996)

\begin{abstract}
Summary - The present review deals with the nutritional and metabolic aspects of postprandial lipemia. The postmeal state is characterized by the accumulation of triglyceride-rich lipoproteins (TRL) in the plasma. This is due to the competition for clearance between hepatically-derived very low density lipoproteins (VLDL) and intestinally-derived chylomicrons. At the same time, an important remodeling of the low density lipoprotein (LDL) and high density lipoprotein (HDL) particles takes place. The amplitude and/or time-course of the occurrence of the postprandial triglyceride response is influenced by the quantity of dietary lipids (triglycerides, cholesterol), the fatty acid composition of dietary triglycerides and the amount and nature of dietary carbohydrates and fibers. The preexisting metabolic status of the subjects markedly influences the postprandial response; ie, hyperlipidemic, diabetic and obese subjects can exhibit an exaggerated increase in triglycerides and lipoprotein remodeling. The hypothesis that postprandial lipid modifications are associated with atheroma deposition and coronary events has been supported by several experimental observations. Despite the significant amount of knowledge already obtained in this field, further research is needed to better elucidate the existing relationships between dietary intake, postprandial response and pathological events.
\end{abstract}

\section{lipid metabolism / lipoproteins / postprandial state / nutrition / pathology}

Résumé - Lipémie postprandiale : aspects nutritionnels et métaboliques. Cette revue traite des aspects nutritionnels et métaboliques de la période postprandiale. L'état postprandial est caractérisé par l'accumulation des lipoprotéines riches en triglycérides dans le plasma, à cause de la compétition existant pour la clairance des lipoprotéines d'origine hépatique (VLDL) et intestinale (chylomicrons). Parallèlement, on assiste à un important remodelage des lipoprotéines $L D L$ et $H D L$. L'amplitude et la cinétique de l'hypertriglycéridémie postprandiale sont modulées par la quantité de lipides alimentaires ingérés (triglycérides, cholestérol), la composition en acides gras des lipides, la nature et

Abbreviations: TRL: triglyceride-rich lipoproteins; VLDL: very low density lipoproteins; LDL: low density lipoproteins; IDL: intermediate density lipoproteins; HDL: high density lipoproteins; LCAT: lecithin-cholesterol-acyl-transferase; CETP: cholesterol ester transfer protein; MUFA: monounsaturated fatty acids; PUFA: polyunsaturated fatty acids; SFA: saturated fatty acids. 
la quantité des sucres et fibres alimentaires. L'état métabolique des sujets influence également la réponse postprandiale; les hyperlipémiques, diabétiques et obèses présentent une hypertriglycéridémie postprandiale exagérée. L'hypothèse suggérant que la formation de la plaque d'athérome et les accidents coronariens pourraient être associés à des modifications postprandiales anormales a été supportée par plusieurs études. Malgré les importantes connaissances déjà obtenues, les recherches restent à poursuivre pour démontrer plus amplement les relations entre habitudes alimentaires, lipémie postprandiale et pathologies.

\section{métabolisme / nutrition / lipides / postprandial / pathologies}

\section{THE POSTPRANDIAL STATE: LIPOPROTEINS IN A TRAFFIC JAM}

In the postabsorptive fasting state (fig 1), the liver secrets very low density lipoproteins (VLDL) which are the most concentrated triglyceride-rich lipoproteins (TRL) found during this period (Grundy and Denke, 1990). These particles contain apolipopro- tein B (apoB)-100, apoCs and apoE. Through the action of lipoprotein lipase and hepatic lipase bound to the capillary beds, triglycerides and phospholipids are steadily hydrolyzed, thus generating remnant particles, ie, intermediate density lipoproteins (IDL) and finally low density lipoproteins (LDL). These latter are taken up by the liver and some extrahepatic tissues via the apoB,E receptors and the scavenger recep-

Metabolism of intestinal and hepatic lipoproteins

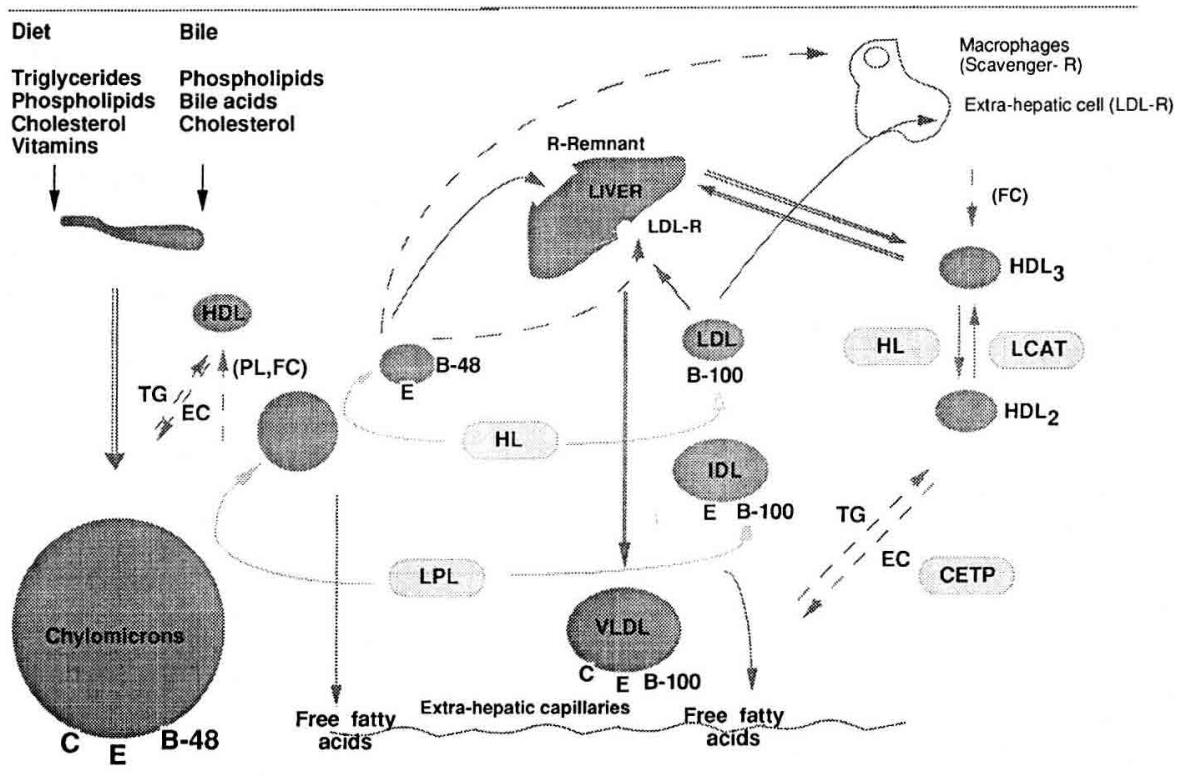

Fig 1. Main metabolic pathways involving hepatic and intestinal triglyceride-rich lipoproteins in the postprandial state. B-100, B-48, E, C: apoproteins B-100, B-48, E and C; TG: triglycerides; PL: phospholipids; FC: free cholesterol; EC: esterified cholesterol; LPL: lipoprotein lipase; HL: hepatic lipase; CETP: cholesterol ester transfer protein; -R: receptor; other abbreviations as on title page. 
tor pathway. At the same time, high density lipoproteins (HDL) are taking up free cholesterol from the peripheral tissues which is then esterified and partly transferred to LDL and VLDL. In the opposite direction, triglycerides can be transferred to HDL and then hydrolyzed before the HDL particles are taken up by hepatocytes to ensure the reverse-routing of cholesterol.

As a result of the efficient digestion and intestinal absorption process, the lipids ingested during a given meal are processed in the enterocyte and resecreted in the form of chylomicrons by the small intestine into the lymph and then into the blood circulation (fig 1). Chylomicrons are the TRL specifically originating from the small intestine during digestion that contain a truncated form of apoB, ie, apoB-48, as well as apoA1 and apoAIV, apoCs and apoE when present in the circulation (Grundy and Denke, 1990; Tall, 1986; Cohn, 1994). The triglycerides of chylomicron particles are hydrolyzed very quickly by capillary-bed lipoprotein lipase and hepatic lipase leaving remnant particles containing apoB-48 and apoE to be taken up by an hepatic remnant receptor and to some extent by the apoB,E receptors and endothelial cells (Tall, 1986; Eisenberg and Sehayek, 1993; Cohn, 1994). The excess surface material of chylomicron particles generated under triglyceride lipolysis is used to convert native $\mathrm{HDL}$ into mature HDL particles.

Thus, the main feature of the postprandial state is the fact that the endogenous TRL (VLDL) and intestinally-derived TRL (chylomicrons) will compete for hydrolysis by the same two enzymes and also partly for removal by hepatic and peripheral cells. The result is clearly a 'traffic jam' occurring during the postmeal rush hours as compared to the fluid equilibrium between secretion and clearance in the fasting state. The nature of the different vehicles deserves a special comment (Gianturco and Bradley, 1991). Chylomicrons are very heavy 'trucks': a par- ticle has a mass of about $50010^{6} \mathrm{Da}$, and it transports about 500000 triglyceride molecules and 60000 cholesterol molecules but has only a very short half-life in the circulation (minutes). Endogenous VLDL are only 'big vans' (particle mass about $3010^{6}$ $\mathrm{Da}, 24000$ triglyceride molecules and 10000 cholesterol molecules) with a halflife of several hours. LDL are small 'cars' (particle mass about $210^{6} \mathrm{Da}, 300$ triglyceride molecules and 2000 cholesterol molecules) with a long half-life (half-day). Careful consideration of such particle specificities may facilitate the understanding of the complexity of this metabolic traffic jam. How to efficiently manage this rush hour is one of the key questions of this review.

One can summarize the importance of the postprandial state as follows: $i$ ) it is a direct consequence of the lipid digestion-absorption process; ii) it reflects the organism's capacity to handle a given dietary lipid input; iii) given the long duration of lipid processing after a usual meal (about 6-8 $\mathrm{h}$ in normal subjects), most of the day is spent in the postprandial state $(14-18 / 24 \mathrm{~h})$ : the postprandial state, and not the fasting state, should be recognized as the usual metabolic state; iv) a dramatic remodeling of lipoprotein particles occurs during this period which results in a decrease in HDL and a significant routing of cholesterol to the liver and peripheral tissues as well as the generation of potentially atherogenic particles.

\section{BASIC FEATURES OF POSTPRANDIAL LIPEMIA}

It has been recognized for years that the interindividual variability in the changes involved in postprandial lipemia after a given test meal is very large (Cohn et al, 1988b). Women as compared to men and subjects without apoE2 phenotype have been shown to have a less marked increase in postprandial triglycerides. 
Postprandial lipemia is characterized by a dramatic increase in plasma triglycerides, phospholipids and free cholesterol and a decrease in cholesterol esters (Dubois et al, 1994a). During the hyperlipidemic state (Cohn et al, 1988b), the concentration of triglycerides increases two to three times in TRL, slightly increases in HDL and slightly decreases in LDL. At the same time, cholesterol concentration increases in TRL and is decreasing in HDL and LDL. In the postabsorptive plasma, a drop in $\mathrm{HDL}_{2}$ but not in $\mathrm{HDL}_{3}$ has been correlated to the magnitude of alimentary lipemia (Patsch et al, 1983). Whereas the apoA1 concentration is not markedly changed postprandially, apoE, apoC and albumin concentrations in TRL are all markedly increased (Cohn et al, 1988a). The relative contribution of the hepatically- or intestinally-derived TRL has been only recently quantitated using immunoaffinity methods with monoclonal antibodies (Cohn et al, 1993; Schneeman et al, 1993). On the whole, the overall postprandial rise in plasma triglycerides is due to a comparable increase in hepatic-apoB-100 TRL and intestinal-apoB-48 TRL, thus illustrating the competition taking place between TRL in the postabsorptive period. The decrease observed in LDL likely results from a reduced lipolysis rate for the parent particles (VLDL) but may possibly be related to an increased cellular uptake in this period. The drop in HDL cholesterol is related to the exacerbated uptake of free cholesterol and esterification by lecithin-cholesterolacyl-transferase (LCAT), the subsequent cholesterol ester transfer protein (CETP)mediated transfert of cholesterol esters to TRL particles (Lagrost, 1994) and quite likely to an increased liver uptake of HDL as well.

It has been demonstrated that the magnitude of postprandial lipemia is positively correlated to fasting triglycerides, VLDL triglycerides and apoCIII (an inhibitor of lipoprotein lipase activity). Conversely, it is negatively correlated to the activity of lipoprotein lipase, apoCII (an activator of lipoprotein (ipase) and postprandial but not fasting insulinemia.

\section{POSTPRANDIAL RESPONSES TO THE AMOUNT AND NATURE OF INGESTED LIPIDS}

Only a few studies have been dedicated thus far to studying the effects of the amount of ingested dietary lipids (Cohen et al, 1988; Dubois et al, 1994a; Murphy et al, 1995). In most studies, an 'oral fat load' has been used, providing $70-150 \mathrm{~g}$ of fat per meal, which is much above the usual range of fat intake even in industrialized countries. Three recent studies have dealt with regular amounts of fat in test meals (Dubois et al, 1994a; Potts et al, 1994; Murphy et al, 1995). In a recently completed study, we compared five different amounts of dietary triglycerides $(0-50 \mathrm{~g})$ in the form of a sunflower emulsion as part of a mixed meal ingested by healthy human subjects. Whereas the no fat and the $15 \mathrm{~g}$ fat meals did not alter the preexisting fasting lipid pattern, the 30,40 and $50 \mathrm{~g}$ fat meals significantly increased the plasma and chylomicron triglyceride levels, as well as the plasma phospholipids and free cholesterol concentrations and lowered plasma cholesterol ester concentrations. These postprandial changes, as well as those of chylomicron and plasma retinyl palmitate, were linearly correlated to the amount of ingested triglycerides in the range $0-50 \mathrm{~g} /$ meal. From these data and that in previous studies (Dubois et al, 1994a), we suggest that an amount of $15 \mathrm{~g}$, or even $20 \mathrm{~g}$ triglyceride per meal, is a threshold level which avoids noticeable changes in plasma lipids and lipoproteins postprandially. In terms of daily diet, the calculated figures obtained from the test meal compositions are $17.4 \%$ energy as fat ( $15 \mathrm{~g} / \mathrm{meal})$ and $29.6-41.2 \%$ energy as fat ( $30-50 \mathrm{~g} / \mathrm{meal})$. 
In another study performed in a group of healthy human subjects, we compared, for the first time, the effects of four different amounts of dietary cholesterol on the postprandial response to a $45 \mathrm{~g}$ fat test meal (Dubois et al, 1994b). We found that 140 mg dietary cholesterol per meal did not change the postprandial pattern obtained after the meal deprived of cholesterol whereas an exacerbated rise in chylomicron triglycerides was observed after meals containing 280 or $710 \mathrm{mg}$ cholesterol. Postprandial changes in several plasma parameters (phospholipids, free and esterified cholesterol) were affected by the amount of dietary cholesterol. The chylomicron lipid composition and apparent size was not influenced by the postprandial concentrations in LDL and HDL free and esterified cholesterol were altered by the amount of cholesterol ingested. As noted earlier for triglycerides, this study indicated that a low amount of dietary cholesterol $(140 \mathrm{mg} / \mathrm{meal}$, ie, about $330 \mathrm{mg} / 2500 \mathrm{kcal} / \mathrm{day}$ ) does not alter the postprandial lipid pattern, whereas higher amounts do. On the whole, these data lead us to suggest that postprandial responses seem appropriate tools to use for setting dietary guidelines.

The effect of the dietary triglycerides fatty acid composition has been the subject of numerous postprandial animal and human studies. Although this question is not completely solved, it is possible to summarize the available literature data. It is essential to realize that two different kinds of experiments have been performed in this respect. In the first type, the daily diet was designed to provide different types of triglyceride fatty acids for weeks and postprandial tests were undertaken in the adapted organisms (Harris et al, 1988; Weintraub et al, 1988). In the second type, subjects or animals were on a standard diet and were given test meals with triglycerides from different sources (Harris et al, 1988; Van Heek and Zilversmit, 1990; Levy et al, 1991; De Bruin et al, 1993; Muesing et al, 1995). A human study during which these two approaches were combined (Weintraub et al, 1988) can be used to summarize this point. Adaptation of subjects to diets containing either saturated fatty acid (SFA), n-6 polyunsaturated fatty acid (PUFA) or n-3 PUFA resulted in a rise in postprandial lipemia in the following increasing order: n-3 PUFA, n-6 PUFA, SFA, after the same test meal. When the subjects ingested test meals containing the same triglyceride source as the one chronically ingested, the differences in postprandial responses were exacerbated. This example is representative of the literature data. The mechanisms behind the effects of chronic diets are likely the following, when PUFA are compared to SFA: i) activity of lipoprotein lipase can be increased; ii) fasting triglyceridemia can be lowered; iii) postprandial clearance is augmented, thus leading to a reduced postprandial lipemia. When subjects are not adapted to various fats but only ingest test meals with different types of triglycerides, the mechanisms involved seems to be i) enrichment of chylomicron lipids in monounsaturated fatty acids (MUFA and PUFA); ii) increase in the chylomicron size; iii) accelerated lipolysis and clearance.

From various studies, and especially those dealing with n-3 PUFA, it appears that the effects of a chronically-enriched diet on postprandial lipemia are clearly more significant than those of a unique test meal.

\section{POSTPRANDIAL LIPEMIA, DIETARY CARBOHYDRATES AND FIBERS}

Few studies have dealt with the effects of dietary carbohydrates on postprandial lipemia in healthy subjects. Adding 50 or $100 \mathrm{~g}$ glucose to a $40 \mathrm{~g}$ fat test meal has been shown to attenuate the postprandial triglyceridemia rise observed with fat alone (Cohen and Berger, 1990). Alterations in postmeal responses could also occur in the 
presence of starch, but the nature of starch, including resistant starch, needs to be taken into careful consideration (Morgan et al, 1993).

Other studies dealt with the effects of dietary fibers on postprandial lipemia and lipoproteins in healthy subjects (Abraham and Metha, 1988; Redard et al, 1990; Cara et al, 1992; Dubois et al, 1993, 1995; Sandström et al, 1994; Anderson et al, 1995). When different sources of fiber were added to combined test meals, lowering of chyIomicron and/or plasma triglycerides and cholesterol levels were observed with oat bran, wheat fiber and germ and pea fiber (Cara et al, 1992; Dubois et al, 1993; Sandström et al, 1994). At the same time, LDL and HDL cholesterol levels were altered. Conversely, following a 2 week supplementation of the subject diet by soluble fibers such as oat bran or psyllium, the supplementation of the test meals had no effects (Abraham and Metha, 1988) or resulted in an increased postprandial triglyceridemia (Anderson et al, 1995; Dubois et al, 1995).

This apparent discrepancy could result from the fact that several mechanisms are likely affected by carbohydrates or fibers during the postprandial period (Lairon, 1996). Carbohydrates and fiber can slow gastric emptying. Some fiber sources can reduce and/or delay lipid emulsification and lipolysis of dietary fat as well as slow the rate of intestinal absorption. Concomitantly, carbohydrates can stimulate intravascular lipolysis as a result of increased postprandial insulinemia whereas the reported reduced elevation in postprandial insulinemia might explain the opposite effect observed after chronic fiber supplementation.

The currently available knowledge and the need for further research on the relationship between nutrients and postprandial lipemia are summarized in table I.

\section{METABOLIC STATUS OF SUBJECTS AND POSTPRANDIAL LIPEMIA}

It has been recognized for years that the preexisting metabolic status of the subjects affects the postprandial response to a meal. Even in the case of normotriglyceridemic subjects $(0.7-1.5 \mathrm{mmol} / \mathrm{L}$ fasting triglycerides), a positive correlation has been

Table I. Postprandial lipemia and nutrients: main aspects.

Amount of dietary lipid: increases postprandial lipemia above threshold level (15-20 g/meal)

Amount of dietary cholesterol: increases postprandial lipemia above threshold level (150 $\mathrm{mg} / \mathrm{meal})$. Needs further evaluation of acute/chronic effects.

Nature of triglycerides: increase in postprandial lipemia: n-3 PUFA $<n-6$ PUFA $<$ SFA; increase in postprandial lipemia: short/medium chain FA $\ll$ long chain FA. Needs further evaluation of acute/chronic effects.

Amount and nature of carbohydrates: dietary glucose and resistant starch could lower postprandial lipemia. Needs further evaluation of acute/chronic effects, especially for starches.

Amount and nature of dietary fibers: sources of viscous fibers (gums, oat bran, legumes) and some wheat fractions can lower postprandial lipemia. Needs further evaluation of acute/chronic effects. 
found between the amplitude of postprandial lipemia and fasting triglyceride levels (Patsch et al, 1983; Cohn et al, 1988b; Dubois et al, 1994a; Potts et al, 1994). In this line, type III and IV hypertriglyceridemic subjects (4-8 $\mathrm{mmol} / \mathrm{L}$ triglycerides) exhibit a markedly amplified postprandial response with a delayed clearance of remnant particles as verified by the retinyl palmitate test (Weintraub et al, 1987). A comparable pattern has been recently reported in patients with familial combined hyperlipidemia (type Ilb). Compared to normolipidemic subjects who showed a triglyceride peak $4 \mathrm{~h}$ after fat-load intake and a return to baseline value after 6 $h$, these patients exhibited a doubled relative postprandial increase after 4-6 $\mathrm{h}$ and returned to baseline only after 9-10 h (Castro Cabezas et al, 1993). An amplified competition for the lipolysis of chylomicrons by lipoprotein and hepatic lipases due to a much increased level of VLDL particles is likely responsible for such observations. An important consequence of this amplified postprandial hypertriglyceridemia is that the amount of cholesterol esters transferred from HDL to TRL is stimulated several-fold (Mann et al, 1991). The limiting factor in this process is the concentration of the CETP in normal subjects (Lagrost, 1994). The rate of transfer is directed by the concentration of TRL in hyperlipidemic subjects. As modeled by Miesenbock and Patsch (1992), the mass of cholesterol esters transferred to TRL during a usual $24 \mathrm{~h}$ period is approximately doubled in a moderately hyperlipidemic subject as compared to a normolipidemic one (3 750 vs $2010 \mathrm{mg} /$ day).

Conversely, hypercholesterolemic subjects without elevated fasting triglycerides (type Ila) do not show an amplified postprandial lipemia or delayed clearance (Weintraub et al, 1987).

In obese subjects with a moderate hypertriglyceridemia (Potts et al, 1995), an amplified rise in postprandial plasma triglycerides has been reported which is due to an increase in both chylomicron and VLDL triglyceride levels. As compared to normal subjects, the metabolic pattern of these obese subjects (Coppack et al, 1992) is characterized by augmented fasting plasma, VLDL triglycerides and insulinemia and postprandially, by an increased postprandial insulinemia, an amplified hypertriglyceridemia (resulting from chylomicron/VLDL competition and a less stimulated lipoprotein lipase) and a reduced decrease in the free fatty acid concentration (adipocyte hormone-sensitive lipase being less repressed and tissue uptake being less stimulated).

In diabetic subjects, augmented postprandial lipemia and delayed clearance has been reported (Syvänne et al, 1994; Attia et al, 1995). A delayed remnant clearance has been observed in diabetic patients as compared to controls even when these patients had a normal fasting triglyceridemia, likely suggesting an impaired TRL handling associated with diabetes.

\section{POSTPRANDIAL LIPEMIA AND ARTERIOSCLEROSIS}

One of the key questions posed to researchers and clinicians is the following: what could be the implication of postprandial events to the formation of the atheroma plaque? Although epidemiological data strongly suggest a relationship between the frequency of coronary events and fasting levels of plasma triglycerides, total and LDL cholesterol, the mechanisms involved are not fully understood (Marckmann et al, 1990; Havel, 1994).

That the mechanisms occurring during the postprandial, rather than in the fasting state, would be implicated in atherogenesis is not, per se, a new concept. Indeed, Zilversmit (1979) stated in 1979 "Atherogenesis: a postprandial phenomenon" that, at that time, the direct atherogenicity of chylomicron remnant particles was implicated. 
More recently, this view has been expanded by Patsch's group (Miesenbock and Patsch, 1992) to a broader concept that triglyceride transport is potentially atherogenic and that an impairment of triglyceride transport and TRL handling in the most critical phase (ie, the postprandial period) could be detrimental. This has lead to "a search for an atherogenic lipoprotein" during postprandial lipemia.

This key concept has recently received significant experimental support from several studies during which patients with clinically attested coronaropathy and matched healthy controls were compared (Simpson et al, 1990; Groot et al, 1991; Patsch et al, 1992; Karpe et al, 1993). While the fasting lipid and apoprotein parameters differed only slightly or not at all between the two groups, postprandial triglyceridemia was reported in three studies to rise to a higher level in patients, especially during the late postprandial hours. In subjects with or without diabetes and coronaropathy, the diabetes status appeared to increase more the postprandial lipemia than the coronaropathy (Syvänne et al, 1994).

Several potentially atherogenic particles that might accumulate during the postprandial phase have been found. Chylomicron remnants, especially when enriched with cholesterol esters, were at the root of the Zilversmit hypothesis (1979). More generally, abnormal triglyceride-enriched TRL particles have been shown to possess the capacity to be taken up by macrophages (Gianturco and Bradley, 1991). In a similar vein, large (Sf 60-400) and intermediate (Sf 20-60) TRL have been shown to accumulate postprandially in the plasma of patients with coronaropathy (Karpe et al, 1993). Small and dense LDL have also been found to accumulate in the postprandial plasma of patients (Attia et al, 1995). LDL particles have also been shown to be modified postprandially as compared to the fasting state (Lechleitner et al, 1994). The resulting LDL possess a higher capability in culture to load endothelial cells with cholesterol and to stimulate intracellular esterification. The main aspects are summarized in table II.

To summarize, a moderate lipid intake associated with efficient triglyceride handling may avoid leading to a significant buildup of atheroma plaque. Conversely, an exaggerated intake of lipids associated with a reduced metabolic capacity can induce an accumulation of TRL remnants, an important remodeling of lipoproteins and transfer of cholesterol esters and finally, to an exag-

Table II. Postprandial lipemia and arteriosclerosis: main metabolic features.

Patients with coronaropathy versus healthy controls

- Postprandial lipemia is augmented

- TRL remnant clearance is delayed

- Some TRL subfractions accumulate preferentially

- TRL remnants are enriched in cholesterol esters

- HDL cholesterol, and especially $\mathrm{HDL}_{2}$, is lowered

- Small/dense LDL are augmented

- Carotid wall thickness is correlated to postprandial lipemia

Other detrimental aspects

- Postprandial LDL and TRL are more reactive towards endothelial cells and macrophages

- Blood viscosity and coagulation factors (factor VII, PAI-1) are correlated to hypertriglyceridemia 
gerated cellular uptake of atherogenic particles.

It thus appears that several relevant pieces of information have been recently obtained which strengthen the concept that postprandial events might be directly involved in atherogenesis. Indeed, when looking at the duration and amplitude of postprandial changes, it is less and less conceivable that atheroma plaque building would not be markedly influenced by the postprandial events. Consequently, fasting plasma lipid parameters could still be considered as useful and relevant clinical tools; however, as far as mechanisms are concerned, postprandial variables are likely to be of crucial relevance.

In conclusion, the postprandial state which normally results from our compulsory and frequent food intake, can now be understood as being the most representative state of lipid metabolism. It results in the interactions of the genetic disposition and metabolic capacity of a given individual as well as the external input of nutrient lipids especially.

This represents a unique 'roundabout' where researchers and clinicians involved in various fields such as nutrition, behavior, metabolism, pathology and epidemiology can 'have a drive' together.

\section{REFERENCES}

Abraham ZD, Metha T (1988) Three-week psyllium-husk supplementation: effect on plasma cholesterol concentrations, fecal steroid excretion, and carbohydrate absorption in men. Am J Clin Nutr 47, 67-74

Anderson JW, O'Neal DS, Riddell-Mason S, Floore TM, Dillon DW, Oeltgen PR (1995) Postprandial serum glucose, insulin, and lipoprotein responses to highand low-fiber diets. Metabolism 44, 848-854

Attia N, Durlach V, Paul JL, Soni T, Betoulle D, GirardGloba A (1995) Modulation of low density lipoprotein subclasses by alimentary lipemia in control and normotriglyceridemic non-insulin-dependent diabetic subjects. Atherosclerosis 113, 197-209
Cara L, Dubois C, Borel P et al (1992) Effects of oat bran, rice bran, wheat fiber, and wheat germ on postprandial lipemia in healthy adults. Am J Clin Nutr $55,81-88$

Castro Cabezas M, De Bruin TWA, Jansen H, Kock JAW, Kortlandt W, Erkelens DW (1993) Impaired chylomicron remnant clearance in familial combined hyperlipidemia. Arterioscler Thromb 13, 804-814

Cohen JC, Berger GM (1990) Effects of glucose ingestion on postprandial lipemia and triglyceride clearance in humans. $J$ Lipid Res 31, 597-602

Cohen JC, Noakes TD, Spinnler Benade AJ (1988) Serum triglyceride responses to fatty meals: effect of meal fat content. Am J Clin Nutr 7, 825-827

Cohn JS (1994) Postprandial lipid metabolism. Curr Op Lipidol 5, 185-190

Cohn JS, McNamara JR, Cohn SD, Ordovas JM, Schaefer EJ (1988a) Postprandial plasma lipoprotein changes in human subjects of different ages. $J$ Lipid Res 29, 469-479

Cohn JS, McNamara JR, Cohn SD, Ordovas JM, Schaefer EJ (1988b) Plasma apolipoprotein changes in the triglyceride-rich lipoprotein fraction of human subjects fed a fat-rich meal. J Lipid Res 29, 925-936

Cohn JS, Johnson EJ, Millar JS, Cohn SD, Milne RW, Marcel YL, Russell RM, Schaefer EJ (1993) Contribution of apoB-48 and apoB-100 trigtyceride-rich lipoproteins (TRL) to postprandial increases in the plasma concentration of TRL triglycerides and retinyl esters. J Lipid Res 34, 2033-2040

Coppack SW, Evans RD, Fisher RM, Frayn KN, Gibbons GF, Humphreys SM, Kirk ML, Potts JL, Hockaday TDR (1992) Adipose tissue metabolism in obesity: lipase action in vivo before and after a mixed meal. Metabolism 41, 264-272

De Bruin TWA, Brouwer CB, Trip M, Van LS, Jansen $H$, Erkelens DW (1993) Different postprandial metabolism of olive oil and soybean oil: a possible mechanism of the high-density lipoprotein-conserving effect of olive oil. Am J Clin Nutr 58, 477-483

Dubois C, Cara L, Armand M, Borel P, Senft M, Portugal H, Pauli AM, Bernard PM, Lafont H, Lairon D (1993) Effects of pea and soybean fibre on postprandial lipaemia and lipoproteins in healthy adults. Eur $J$ Clin Nutr 47, 508-520

Dubois C, Armand M, Azais-Braesco V, Portugal $H$, Pauli AM, Bernard PM, Latgé C, Lafont $H$, Borel P, Lairon D (1994a) Effects of moderate amounts of emulsified dietary fat on postprandial lipemia and lipoproteins in normolipidemic adults. Am J Clin Nutr 60, 374-382

Dubois C, Armand M, Mekki N, Portugal H, Pauli AM, Bernard PM, Lafont H, Lairon D (1994b) Effects of increasing amounts of dietary cholesterol on postprandial lipemia and lipoproteins in human subjects. $J$ Lipid Res 35, 1993-2007 
Dubois C, Armand M, Senft M, Portugal H, Pauli AM, Bernard PM, Lafont $H$, Lairon D (1995) Chronic oat bran intake alters postprandial lipemia and lipoproteins in healthy adults. Am J Clin Nutr 61, 325-333

Eisenberg S, Sehayek E (1993) Cellular metabolism of triglyceride-rich lipoproteins and their remnants. In: Treatment of Severe Dyslipoproteinemia in the Prevention of Coronary Heart Disease (AM Gotto Jr, M Mancini, WO Richter, P Schwandt, eds), 4th Int Symp Munich 1992, Karger, Basel, 27-36

Gianturco SH, Bradley WA (1991) A cellular basis for the atherogenicity of triglyceride-rich lipoproteins. Atherosclerosis Rev 22, 9-14

Groot PHE, Van Stiphout WAHJ, Krauss XH, Jansen $H$, Van Tol A, Van Ramshorst E, Chin-On S, Hofman A, Cresswell SR, Havekes L (1991) Postprandial lipoprotein metabolism in normolipidemic men with and without coronary artery disease. Arterioscler Thromb 11, 653-662

Grundy SM, Denke MA (1990) Dietary influences on serum lipids and lipoproteins. J Lipid Res 31, 11491172

Harris WS, Connor WE, Alam N, Illingworth DR (1988) Reduction of postprandial triglyceridemia in humans by dietary $n-3$ fatty acids. J Lipid Res 29, 1451-1460

Havel R (1994) Triglyceride-rich lipoproteins and atherosclerosis - new perspectives. Am J Clin Nutr 59, 795-799

Karpe F, Bard JM, Steiner G, Carlson LA, Fruchart JC, Hamsten A (1993) HDLs and alimentary lipemia. Studies in men with previous myocardial infarction at a young age. Arterioscler Thromb 13, 11-22

Lagrost $L$ (1994) Regulation of cholesteryl ester transfer protein (CETP) activity: review of in vitro and in vivo studies. Biochim Biophys Acta 1215, 209-236

Lairon D (1996) Dietary fibers: effects on lipid metabolism and mechanisms of action. Eur J Clin Nutr 50, 125133

Lechleitner M, Hoppichler F, Föger B, Patsch JR (1994) Low-density lipoproteins of the postprandial state induce cellular cholesteryl ester accumulation in macrophages. Arterioscler Thromb 14, 1799-1807

Levy E, Roy CC, Goldstein R, Bar-On H, Ziv E (1991) Metabolic fate of chylomicrons obtained from rats maintained on diets varying in fatty acid composition. J Am Coll Nutr 10, 69-78

Mann CJ, Yen FT, Grant AM, Bihain BE (1991) Mechanism of plasma cholesteryl ester transfer in hypertriglycerimedia. J Clin Invest 88, 2059-2066

Marckmann P, Sandström B, Jespersen J (1990) Effects of total fat content and fatty acid composition in diet on factor VII coagulant activity and blood lipids. Atherosclerosis 80, 227-233

Miesenböck G, Patsch JR (1992) Postprandial hyperlipidemia: the search for the atherogenic lipoprotein. Curr Op Lipidol 3, 196-201
Morgan LM, Tredger JA, Shavila Y, Travis JS, Wright J (1993) The effect of non-starch polysaccharide supplementation on circulating bile acids, hormone and metabolite levels following a fat meal in human subjects. Br J Nutr 70, 491-501

Muesing RA, Griffin P, Mitchell P (1995) Corn oil and beef tallow elicit different postprandial responses in triglycerides and cholesterol, but similar changes in constituents of high-density lipoprotein. $J$ Am Coll Nutr $14,53-60$

Murphy MC, Isherwood SG, Sethi S, Gould BJ, Wright JW, Knapper JA, Williams CM (1995) Postprandial lipid and hormone responses to meals of varying fat contents: modulatory role of lipoprotein lipase? Eur $J$ Clin Nutr 49, 579-588

Patsch J, Karlin JB, Scott LW, Smith LC, Gotto AM Jr (1983) Inverse relationship between blood levels of high density lipoprotein subfraction-2 and magnitude of postprandial lipemia. Proc Natl Acad Sci USA $80,1449-1453$

Patsch JR, Miesenbock G, Hopferwieser T et al (1992) Relation of triglyceride metabolism and coronary artery disease. Studies in the postprandial state. Arteric scler Thromb 12, 1336-1345

Potts JL, Humphreys SM, Coppack SW, Fisher RM, Gibbons GF, Frayn KN (1994) Fasting plasma triacylglycerol concentrations predict adverse changes in lipoprotein metabolism after a normal meal. $\mathrm{Br} J$ Nutr 72, 101-109

Potts JL, Coppack SW, Fisher RM, Humphreys SM, Gibbons GF, Frayn KN (1995) Impaired postprandial clearance of triacylglycerol-rich lipoproteins in adipose tissue in obese subjects. Am J Physiol 268, E588-E594

Redard CL, Davis PA, Schneeman BO (1990) Dietary fiber and gender: effect on postprandial lipemia. $A m$ J Clin Nutr 52, 837-845

Sandström B, Hansen LT, Sorensen A (1994) Pea fiber lowers fasting and postprandial blood triglyceride concentrations in humans. J Nutr 124, 2386-2396

Schneeman BO, Kotite L, Todd KM, Havel RJ (1993) Relationships between the responses of triglyceriderich lipoproteins in blood plasma containing apolopoproteins B-48 and B-100 to a fat-containing meal in normolipidemic humans. Proc Natl Acad Sci USA 90, 2069-2073

Simpson HS, Williamson CM, Olivecrona T, Pringle S, Maclean J, Lorimer AR, Bonnefous F, Bogaievsky Y, Packard CJ, Shepherd J (1990) Postprandial lipemia, fenofibrate and coronary artery disease. Artherosclerosis $85,193-202$

Syvänne M, Hilden H, Taskinen MR (1994) Abnormal metabolism of postprandial lipoproteins in patients with non-insulin-dependent diabetes mellitus is not related to coronary artery disease. J Lipid Res 35, 15-26

Tall AR (1986) Metabolism of postprandial lipoproteins. Methods Enzymol 129, 469-482 
Van Heek M, Zilversmit DB (1990) Postprandial lipemia and lipoprotein lipase in the rabbit are modified by olive and coconut oil. Arteriosclerosis 10, 421-429

Weintraub MS, Eisenberg S, Breslow JL (1987) Different patterns of postprandial lipoprotein metabolism in normal, type Ila, type III, and type IV hyperlipoproteinemic individuals; effect of treatment with cholestryramine and gemfibrozil. J Clin Invest 79, 1110-1119

Weintraub MS, Zechner R, Brown A, Eisenberg S, Breslow JL (1988) Dietary polyunsaturated fats of the w6 and $w-3$ series reduce postprandial lipoprotein levels. J Clin Invest 82, 1884-1893

Zilversmit DB (1979) Atherogenesis: a postprandial phenomenon. Circulation 60, 473-485 